\title{
A Demographic Profile Of Children Diagnosed With Coeliac Disease Presenting To The Paediatric Clinic At Queen's Hospital Burton Upon Trent From 2005 To 2017
}

\author{
Ahmed M, Singavarapu R and Muogbo D \\ University Hospitals of Derby and Burton, United Kingdom
}

\section{Background and Aims}

Coeliac disease is an immune-mediated systemic disorder elicited by gluten \& related prolamins in genetically susceptible individuals. In the United Kingdom, 1 in 100 individuals are affected. It is estimated that only a quarter with this condition are currently clinically diagnosed. In children, delayed diagnosis can lead to growth failure, delayed puberty and dental problems.

We analysed demographic profile and clinical presentation of children with coeliac disease that presented to the paediatric clinic.

\section{Methods}

All children ( $<18$ years) with confirmed coeliac disease diagnosed over a 13 year period (2005-2017) at the Queen's Hospital, Burton were studied retrospectively. Information was retrieved from the electronic medical records and pathology results.

\section{Results}

In total, 70 (53\% females) children had the confirmed diagnosis of coeliac disease (chart 1 ). Median age at diagnosis between 2005-2010 was 3 years and 3 months. This increased to 6 years and 9 months between 2011-2017 (Chart 2). Classical disease was present in $77 \%$, (54 patients) whereas $23 \%$ (16 patients) had either non-classical presentations or belonged to high risk group such as those with Type- 1 diabetes, positive family history or autoimmune disease (Chart 3). Abdominal pain was the most common presentation followed by iron deficiency anaemia and chronic diarrhoea.

\section{Conclusions}

The median age at diagnosis of coeliac disease more than doubled between the first and second part of the study period. Coeliac disease may present with non-gastrointestinal symptoms. Low threshold needs to be maintained for further diagnostic work up at all ages, even with atypical presentation and in high risk group in order to avoid long term complications associated with delayed diagnosis.

\section{References}

1. nice.org.uk/guidance/qs134

2. https://www.coeliac.org.uk/

3. JPGN 2012;54:136-160

4. Am J Gastroenterol 2002; 97:695-99

5. JPGN 2017;64(2):175-9
Chart 1: Male to female ratio $(\mathrm{N}=70)$

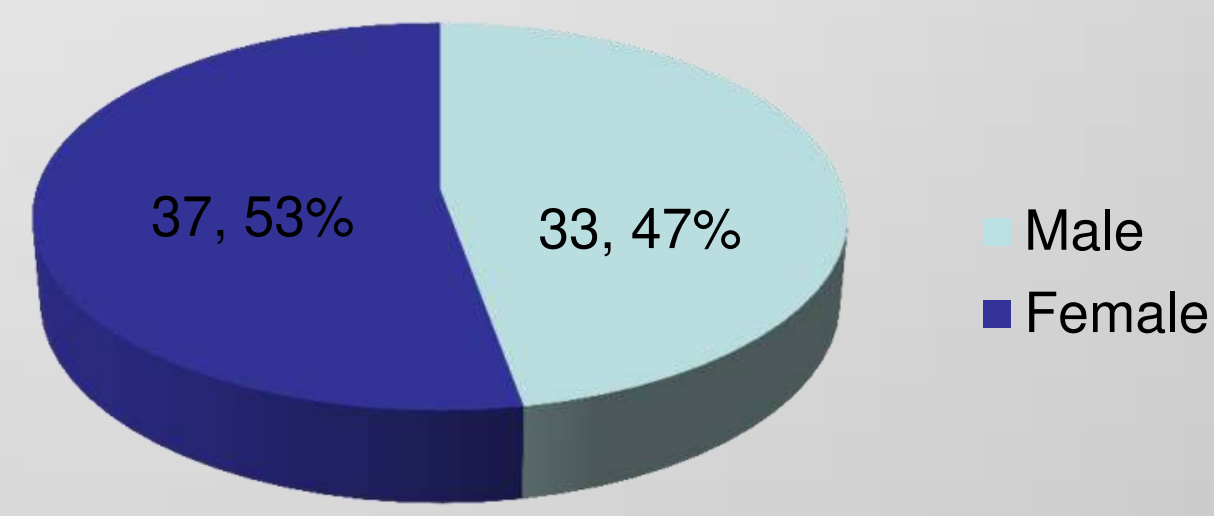

Chart 2: Median age at diagnosis (in years)

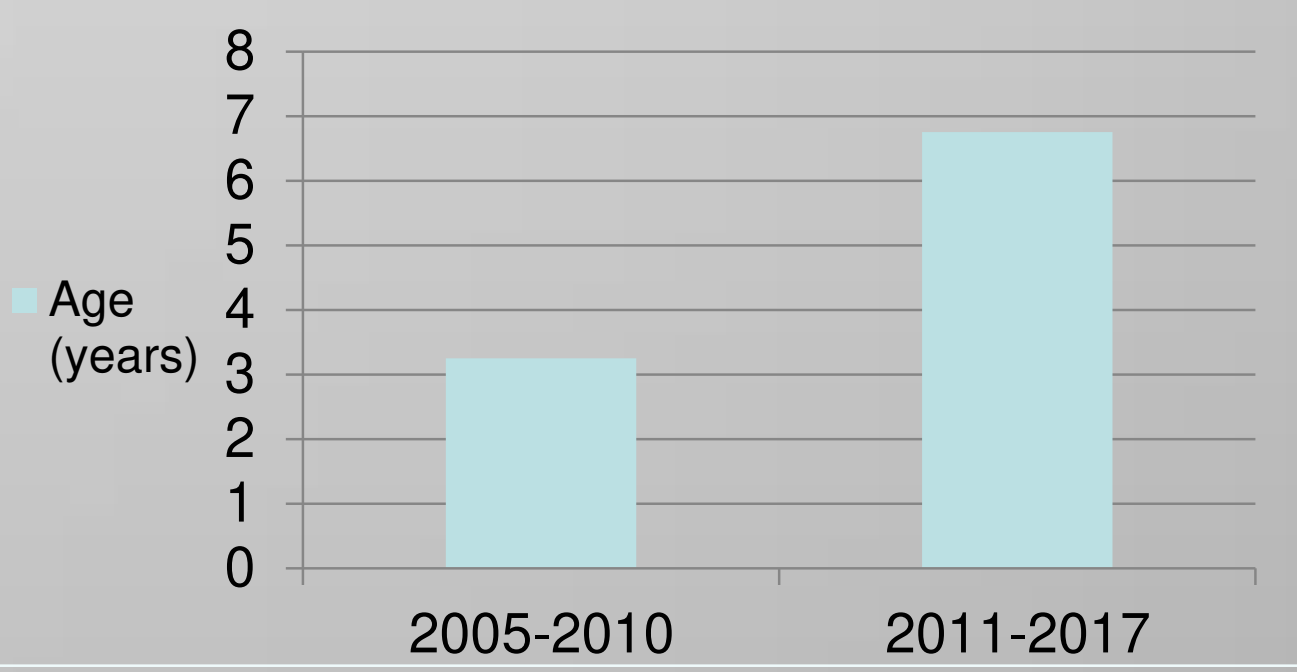

Chart 3: Symptoms

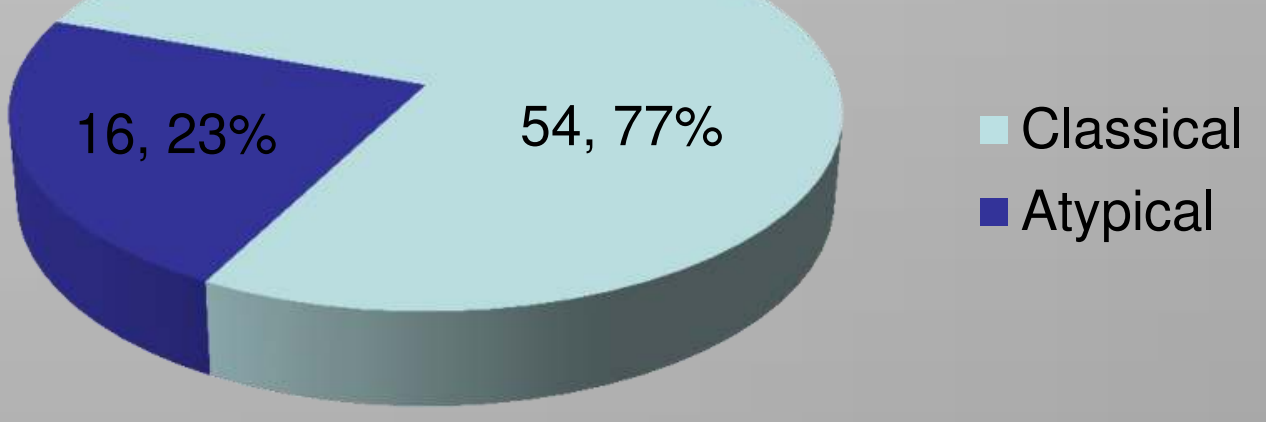

Table 1: Presentation

\begin{tabular}{|c|c|c|}
\hline & Number & $\%$ \\
\hline Abdominal pain & 32 & 46 \\
\hline Iron deficiency anaemia & 20 & 29 \\
\hline Chronic diarrhoea & 19 & 27 \\
\hline Positive family history & 13 & 19 \\
\hline Short Stature & 5 & 7 \\
\hline Faltering growth & 4 & 6 \\
\hline Type 1 diabetes & 4 & 6 \\
\hline Constipation & 3 & 4 \\
\hline Miscellaneous & 12 & 17 \\
\hline
\end{tabular}

